\title{
GRADO DE CONOCIMIENTO SOBRE EL PROBLEMA DE LOS REFUGIADOS Y ACTITUDES HACIA ELLOS
}

\author{
Eva Sánchez Vadillo \\ Educadora Social \\ evasanv95@gmail.com \\ Ana Isabel Isidro de Pedro \\ Profesora Titular de E.U. \\ Departamento de Psicología Social y Antropología. \\ Universidad de Salamanca \\ anyis@usal.es
}

Fecha de Recepción: 29 Marzo 2018

Fecha de Admisión: 10 Abril 2018

\section{RESUMEN}

La problemática de los refugiados es un tema complejo que en los últimos años ha cobrado mayor visibilidad y cobertura mediática, de manera que -aunque sea de forma indirecta- está presente de manera habitual en nuestras vidas. El tema no es una novedad porque tener que abandonar el propio país por motivo de persecución fundada ha sido recurrente a lo largo de la Historia. Y, sin embargo, en pleno siglo XXI, nos enfrentamos a una grave crisis humanitaria. Frente a ello, y por lo que a aspectos psicosociales se refiere, no siempre el nivel de conocimiento de la población y el grado de sensibilización hacia el tema son los adecuados. En el presente trabajo se pretende analizar, mediante una investigación de tipo descriptivo, el nivel de conocimientos sobre la temática, el grado de sensibilización y empatía hacia los refugiados, el nivel de involucración y la opinión con respecto a la situación de los mismos que presenta una muestra de sujetos. Para ello, se utilizó un cuestionario de elaboración propia, conformado por preguntas abiertas, cerradas y tipo Likert, que fue aplicado a una muestra de 60 sujetos (29 mujeres y 31 hombres). Los resultados revelan que, en la muestra analizada, el grado de conocimiento hacia el tema es mucho más escaso de lo que, en principio, cabría esperar y, no obstante, las actitudes de algún modo prejuiciosas parecen ser evidentes.

Palabras clave: refugiados; empatía; conflicto; educación

\section{ABSTRACT}

Degree of knowledge about the refugee problem and attitudes toward them.

The problem of refugees is a complex matter that in recent years has gained greater visibility and media coverage, so that -even though indirectly- it is regularly present in our lives. The matter 
is not a novelty because having to leave the own country due to persecution has been recurrent throughout the History. But, in broad of the 21 st century, we are facing a serious humanitarian crisis. Faced with this, and as far as psychosocial aspects are concerned, not always the level of knowledge of the population and the degree of sensitivity towards the subject are the adequate. In the present work it is tried to analyze, by means of a descriptive investigation, the level of knowledge on this subject, the degree of sensitivity and empathy towards the refugees, the level of involvement and the opinion regarding the situation of the same ones that present a sample of individuals. To do this, a developed by the authors questionnaire was used, consisting of open, closed and Likert-type questions, which was applied to a sample of 60 individuals (29 women and 31 men). The results found reveal that, in the analyzed sample, the degree of knowledge towards this subject is much scarcer than, in principle, it could be expected and, even so, the attitudes in some way prejudiced seem to be evident.

Keywords: refugees; empathy; conflict; education

\section{ANTECEDENTES}

Para empezar, quizá lo primero que deberíamos tener claro es la diferencia entre los conceptos 'refugiado' y 'desplazado' ya que, a menudo, se utilizan indistintamente cuando, de hecho, no se refieren a lo mismo.

En la Convención sobre el Estatuto de los Refugiados de las Naciones Unidas de 1951, artículo 2, se define 'refugiado' como aquella persona que:

Debido a fundados temores de ser perseguida por motivos de raza, religión, nacionalidad, pertenencia a determinado grupo social u opiniones políticas, se encuentre fuera del país de su nacionalidad y no pueda 0 , a causa de dichos temores, no quiera acogerse a la protección de tal país; 0 que, careciendo de nacionalidad y hallándose, a consecuencia de tales acontecimientos, fuera del país donde antes tuviera su residencia habitual, no pueda 0 , a causa de dichos temores, no quiera regresar a él (p. 7)

En este mismo sentido, el Alto Comisionado de las Naciones Unidas para los Refugiados (ACNUR) refiere que:

Un refugiado abandona su país por la amenaza de persecución y no puede regresar en condiciones de seguridad, a menos que se dé un cambio fundamental en la situación existente (por ejemplo, un acuerdo de paz duradero 0 un cambio de gobierno (ACNUR, 2005, s.p.)

Por su parte, el término 'desplazado' podríamos definirlo como aquella persona que debido a cuestiones bélicas, religiosas, políticas, entre otras, debe abandonar su hogar pero no llega a salir de su país.

Los desplazados internos no han cruzado una frontera internacional para buscar seguridad, sino que han permanecido en sus propios países. Incluso si han huido por las mismas razones que los refugiados (conflicto armado, violencia generalizada, violaciones de derechos humanos), los desplazados están legalmente bajo la protección de su propio gobierno, incluso cuando el gobierno pueda ser la causa de su huida. Como ciudadanos, mantienen todos sus derechos y protección que contempla tanto la legislación de derechos humanos como bajo el derecho internacional humanitario (ACNUR, 2008, p. 6).

Si la amenaza se da en una zona concreta de su país, la persona o grupo de personas pueden mudarse a otra parte dentro de su propio país, siendo desplazados, y allí el Estado los protegerá. Normalmente este hecho se da en circunstancias concretas en las que el Estado no es el agente que Ios amenaza. Esto sucede, por ejemplo, en países donde hay grupos guerrilleros que controlan algún territorio dentro de esos países. Como es el caso de Sudán del Sur. 
Cabe mencionar, también, otra definición relevante, cual es 'solicitante de asilo', entendiendo por tal a aquella persona que solicita el reconocimiento de la condición de refugiado, aunque esta solicitud todavía no haya sido evaluada de forma definitiva (ACNUR, s.f.). En este sentido, muchos autores afirman que el término 'refugiado' se está empleando de manera incorrecta, ya que la mayoría de las veces cuando se emplea este término nos estamos refiriendo a 'solicitantes de asilo. Sin embargo, el término 'refugiado' se ha extendido y se utiliza mayoritariamente. Esto también se debe al uso del término por parte los medios de comunicación, Ilevando a popularizar y generalizar el concepto.

ACNUR (2005) afirma que un refugiado tiene derecho de asilo en condiciones de seguridad. Sin embargo, la protección internacional incluye, además, derecho a recibir, al menos, la ayuda básica y los mismos derechos que cualquier otro extranjero que sea residente legal. Al igual que poseen derechos civiles básicos, como la libertad de pensamiento, de movimiento y el derecho al respeto como persona, podrán acceder, de igual forma, a los derechos económicos y sociales, tal y como lo hacen el resto de ciudadanos: derecho a asistencia médica, asistencia material y asistencia física, derecho al acceso a los tribunales de justicia, derecho a la reunificación familiar y al acceso a medios especiales en casos particulares de vulnerabilidad. De igual forma, el reconocimiento de refugiado conlleva el acceso al derecho de protección contra la devolución -no se les podrá devolver a los países de los que proceden si su vida o su libertad corren peligro, salvo excepciones (si una persona supone un peligro para el país por ser una amenaza o por ser condenado por un delito grave)-.

Tanto los Estados como ACNUR tienen la obligación de proporcionar protección internacional a los refugiados; para ello hay un proceso en el que se deben seguir las leyes del país de acogida y los criterios que determinarán su estado como refugiado. Todo es más sencillo si se tienen documentos de identidad, aunque muchas veces no es así y el país de asilo debe emitir estos documentos.

Además de los derechos ya mencionados, cabe destacar los siguientes (Comité Español de ACNUR (s.f.):

- No castigo por entrada irregular al país. En situaciones de éxodos masivos se dan situaciones de ingreso al país de manera irregular, lo cual puede verse como motivo para ser deportados 0 devueltos a sus lugares de procedencia. Los países de acogida deberán tener en cuenta la excepcionalidad de la situación y brindarles acceso a derechos básicos.

- Empleo remunerado. Una vez identificados, los refugiados tienen derecho a optar a un empleo digno con el cual puedan garantizar su manutención y a un salario con el que cubrir sus necesidades.

- Vivienda digna. Durante el tiempo en el que los refugiados se encuentren en el país receptor, tendrán derecho a una vivienda digna. Por lo general, los gobiernos destinan fondos para la creación centros de acogida o campamentos para llevar a cabo la acogida, aunque tales medidas son temporales. Otras veces, aunque en menor medida, se logra avanzar hacia soluciones como la entrega de viviendas de protección social.

- Educación pública y gratuita. Los países receptores deben garantizar el derecho a una educación gratuita y de calidad a los menores durante su estancia.

- Libertad de religión. Los países de acogida otorgarán a los refugiados el mismo trato favorable que otorgan a sus ciudadanos nacionales en cuanto a la libertad de religión y de culto.

- Obtención de documentos de identidad y viajes. Al igual que no se podrá restringir la libre circulación de los refugiados en el país de acogida, tampoco se les negará el derecho a la obtención de un documento de identidad o de viaje, ya que esto les permitirá ser identificados y confirmar su situación de refugiados ante las distintas figuras de autoridad y agentes sociales. 


\section{GRADO DE CONOCIMIENTO SOBRE EL PROBLEMA DE LOS REFUGIADOS Y ACTITUDES HACIA ELLOS}

\section{OBJETIVOS}

Se plantean como objetivos generales:

- Descubrir las opiniones que tienen los ciudadanos en cuanto a la problemática de los refugiados.

- Definir la importancia de la educación tanto para las personas que buscan refugio como para las personas nativas de los países acogedores.

\section{METODOLOGÍA}

Para llevar a efecto este trabajo, se ha empleado una metodología cuantitativa descriptiva. Así, el instrumento de medida utilizado ha sido un cuestionario de elaboración propia, integrado por 14 ítems - de preguntas abiertas, cerradas y tipo Likert-, además de las preguntas que revelan variables genéricas. Con él se ha pretendido sondear el nivel de conocimiento que, a nivel general, tiene la muestra acerca de la situación de los refugiados.

Para conseguir una mayor difusión del cuestionario se hizo uso tanto de las nuevas tecnologías -empleando la herramienta de los formularios de Google- como del tradicional formato papel, para llegar a una muestra más representativa, dado que no todo el mundo dispone o domina las nuevas tecnologías.

El cuestionario ha sido cumplimentado finalmente por una muestra de 60 personas, residentes en la provincia de Salamanca, cuyas respuestas se han analizado y comparado utilizando el programa de software libre PSPP y Microsoft Excel para realizar los gráficos.

Para que el análisis nos mostrara una información más detallada, se han diferenciado las respuestas según el sexo y la edad. A este respecto, el cuestionario ha sido contestado, aproximadamente por el mismo número de hombres $(51,66 \%)$ que de mujeres $(48,33 \%)$. Y, puesto que queríamos comprobar si la variable edad es determinante, se han diferenciado cinco segmentos de edad: menores de 25 años, entre 25 y 35 años, entre 36 y 50 años, entre 51 y 60 años y mayores de 60 años. Como se aprecia en la Figura 1, aunque los porcentajes han estado bastante equilibrados, debemos destacar que el rango de edad que más ha respondido al cuestionario es el de menores de 25 años y, por el contrario, el segmento que lo ha hecho en menor medida es el de mayores de 60 años. Esto puede deberse a que los menores de 25 tienen más facilidad de responder mediante las nuevas tecnologías y los mayores de 60 no.

Figura 1. Distribución de la muestra según la edad

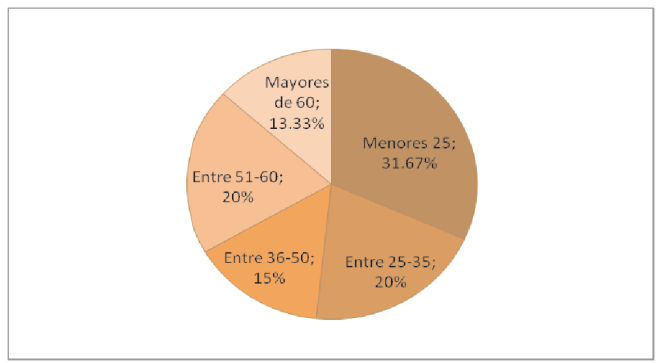




\section{RESULTADOS Y DISCUSIÓN}

A continuación procederemos a analizar y reflejar de forma gráfica los resultados obtenidos a partir del análisis de los datos.

Ante la pregunta que de si conoce la problemática de los refugiados, hemos encontrado una absoluta unanimidad (ver Figura 2). Todos los encuestados afirman conocer la problemática de los refugiados, aunque inicialmente no sabemos en qué medida o con qué grado de profundización.

Figura 2. Conocimiento de la problemática

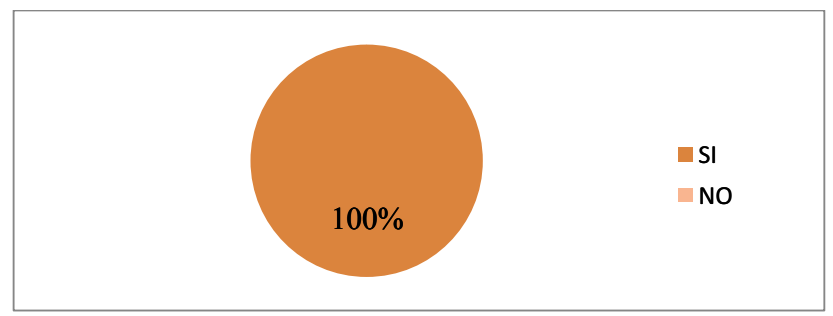

En este sentido, proporcionamos a los encuestados una definición y les pedimos que decidieran si consideraban que acercaba más al término de refugiado 0 al de inmigrante. La definición era la siguiente: "Persona que sale de su país en busca de una vida mejor". El $37 \%$ de las personas afirmó que la definición se refería al término refugiado, mientras que el $63 \%$ determinó que se trataba de inmigrante (ver Figura 3). La definición aportada puede parecer muy general, en realidad lo es. El refugiado abandona su país porque su vida corre peligro; evidentemente, busca una vida mejor, pero si su vida no estuviera en peligro es muy probable que no se marchara. Así, encontramos que, al menos, casi el $40 \%$ no sabe cuál es la mayor diferencia entre estos dos términos.

Figura 3. Definición de inmigrante y diferencia con el término refugiado

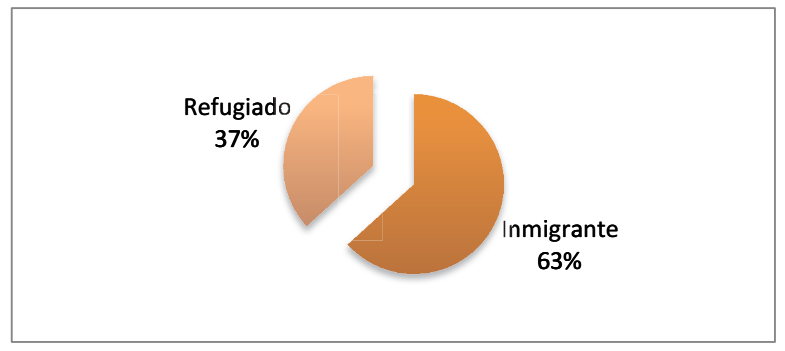

La variable género nos ha proporcionado un dato curioso. Casi la mitad de los hombres de la muestra (el 48,39\%) consideró que la definición hacía referencia al término refugiado, mientras que en las mujeres tan solo fue el $24,14 \%$. Por su parte, la variable de la edad no nos ha proporcionado en este caso ningún dato que nos pudiera indicar que ésta ha sido significativa a la hora de responder.

Por otra parte, una amplia mayoría afirma no conocer personalmente a ningún refugiado (ver Figura 4), por lo que es fácil suponer que los conocimientos que tienen sobre el tema estarán basa- 
dos en la información proporcionada a través de los medios de comunicación o, en menor medida, de alguna persona u organismo que se dedique a trabajar en ámbitos relacionados con el tema.

Figura 4. Conocimiento de algún caso de manera personal

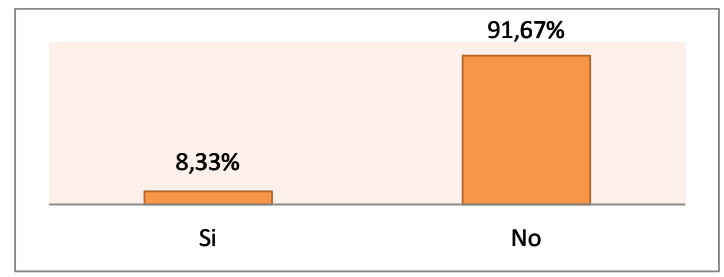

La terrible situación por la que pasan los refugiados y la cobertura mediática del tema nos llevó a suponer que los sujetos, en algún momento de sus vidas, se habrían detenido a pensar y a ponerse en el lugar de las personas que buscan refugio. Sin embargo, tan solo el $52 \%$ de los integrantes de la muestra afirma haber dedicado algún tiempo a eso y manifiesta haberse puesto alguna vez en su piel (ver Figura 5).

Figura 5. Nivel de empatía reconocido por la muestra

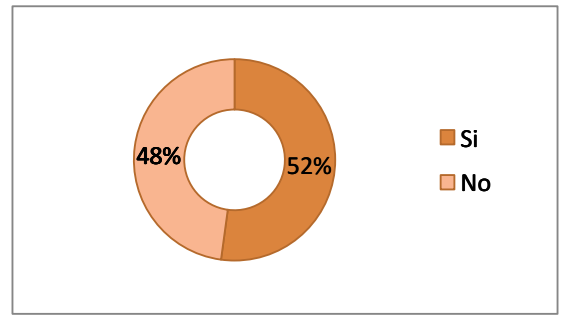

No hay grandes diferencias en cuanto al género se refiere, por lo que no podemos decir que sea una variable significativa en esta cuestión. Sin embargo, la edad sí que nos revela algunas diferencias de interés (ver Figura 6). Los menores de 25 años son los que más empatía dicen sentir hacia los refugiados. Por el contrario, son aquéllos de entre 26 y 35 los que muestran el menor grado de empatía, seguidos muy de cerca de quienes se sitúan en el rango de edad entre 36 y 50 años.

Figura 6. Nivel de Empatía de la muestra por segmentos de edad

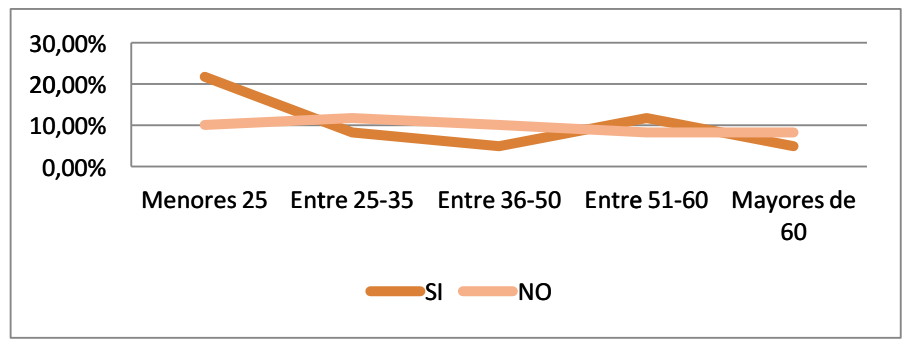


A continuación, se les preguntó si veían este problema como una situación que podría afectar a los ámbitos social, laboral y económico o si, por contra, consideraban que no afectaba a ninguno de ellos. Las respuestas fueron bastante diversas, destacando (51\%) las relacionadas con el ámbito económico. Es muy probable que la gente crea que al acoger a más gente y al tratar de ayudarles es necesario incrementar el dinero destinado para ello. Sólo un $5 \%$ de los sujetos afirmaron que creían que no afectaba a ninguno de estos ámbitos. Al analizar los datos respecto a la edad y el género pudimos comprobar que no existían grandes diferencias, por lo que no las hemos considerado significativas a la hora de responder.

Por otra parte, para comprobar cuanto interés muestran los ciudadanos a la hora de prestar su ayuda, se les preguntó acerca de si conocían entidades u organizaciones que trabajan en este ámbito. A este respecto, tal como se refleja en la Figura 7 , el $71,67 \%$ de la muestra refiere no conocer ninguna organización que trabaje en este campo. Y del 26,67\% restante-que afirmó conocer alguna- sólo un $15 \%$ supo nombrar correctamente alguna entidad. La variable género no revela gran significatividad en esta cuestión. Sin embargo, la edad sí: del 26,67\% que respondió de manera positiva, el $55,5 \%$ se situaba en el rango de edad de entre 25 y 35 años y el $33,3 \%$ formaba parte del grupo de entre 51 y 60 años.

Figura 7. Conocimiento de Entidades u Organizaciones especializadas

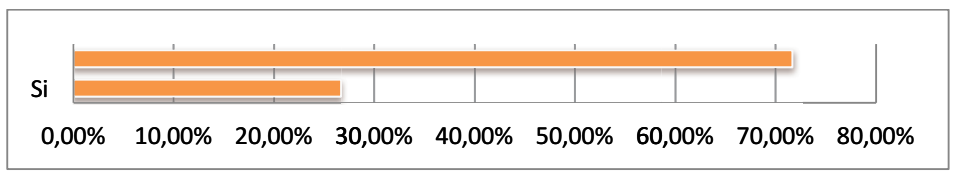

A continuación se sondeaba el nivel de conocimiento acerca de los refugiados, cuestionándoles acerca de los países de procedencia de los mismos, es decir, qué países son los que están sufriendo este éxodo masivo de sus ciudadanos. Al respecto, sólo un $63 \%$ supo enunciar algún país del que procedieran refugiados. Y de este 63\%, el $81 \%$ sólo pudo nombrar a Siria. En el extremo contrario, tan sólo un exiguo 2\% añadió países como Sudán o Somalia. Esto indica que las personas no están correctamente informadas. Como ahora los refugiados procedentes de Siria aparecen más en los medios de comunicación, parecería que la gente se olvida de que existen otros países que también están sufriendo esta situación.

Respecto a la siguiente cuestión, formulada en escala tipo Likert de 5 puntos, sobre si debemos intervenir, como terceros, en esta situación 0, por el contrario, debemos dejar que sean ellos mismos quienes busquen una solución a este problema, el 33,3\% no es capaz de decidir si debemos 0 no intervenir, mientras que el $23,33 \%$ está totalmente de acuerdo en que se debería intervenir y el $11,67 \%$ está totalmente en desacuerdo sobre una intervención al respecto (ver Figura 8).

Figura 8. El problema se debe solucionar en los países de origen sin la intervención de terceros países

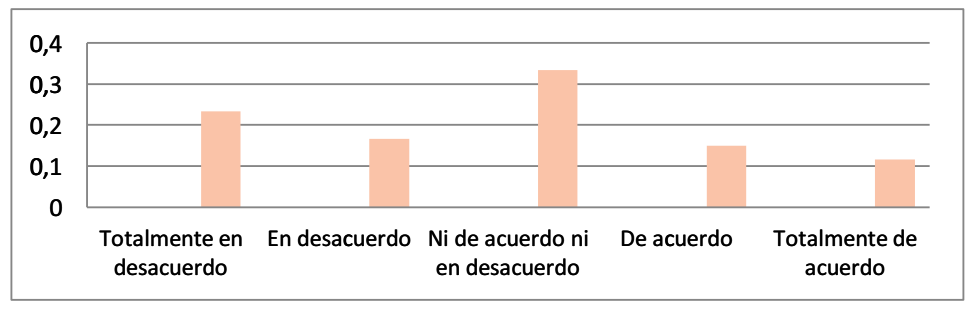


Por lo que se refiere a la pregunta de si consideran que esta situación puede afectar al trabajo de las personas nativas de los países receptores, al propio 0 al de sus familiares, se advierte (ver Figura 9) que un alto porcentaje de aquéllos cree que sí se van a ver afectados, estando de acuerdo $(28,33 \%)$ o totalmente de acuerdo $(6,67 \%)$. El $26,67 \%$ de los sujetos no tiene una opinión al respecto $\mathrm{y}$, de entre los que creen que los empleos no se van a ver afectados por la recepción de refugiados, el $23,33 \%$ está totalmente en desacuerdo con la afirmación planteada y el $15 \%$ en desacuerdo.

Figura 9. La recepción de refugiados puede afectar al trabajo propio o al de familiares

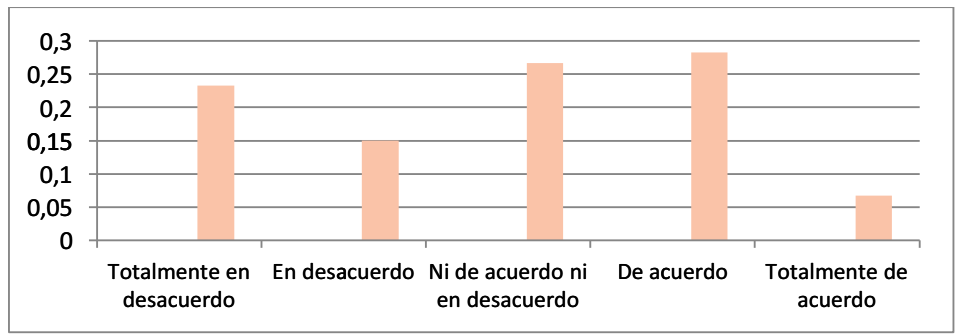

A este respecto, en algunos de los cuestionarios que realizamos en papel nos encontramos con anotaciones añadidas como "nos van a quitar el trabajo", "vergüenza me daría que les dieran trabajo cuando en España no hay ni para nosotros" y, por otro lado, observamos anotaciones como: "puede que tengamos que trabajar más para poder aumentar los ingresos que se destinan a estas ayudas" o "vienen por seguridad, no a quitarnos el trabajo".

A menudo vemos en las noticias la comisión de actos de racismo y delitos de odio 0 el aumento de la ideología xenófoba. En este sentido, se ha realizado la pregunta de si consideran que la llegada de personas que buscan asilo tiene que ver con estos hechos y puede estar fomentando el racismo y los movimientos xenófobos. De acuerdo con la Figura 10, el $73,34 \%$ de los encuestados asegura que sí tiene relación, estando de acuerdo $(26,67 \%)$ o totalmente de acuerdo $(46,67 \%)$ con la afirmación. Tan solo el 10\% está en desacuerdo y el 1,67\% totalmente en desacuerdo. Suponiendo el $15 \%$ quienes no se decantan en uno u otro sentido. Esto puede deberse a que, mayoritariamente, los refugiados suelen ser de culturas diferentes a las de los países receptores y esto provoca un fuerte choque entre culturas, ya que no todo el mundo acepta la convivencia intercultural. Además, la situación se ha visto agravada por los terribles actos terroristas que provocan miedo e inseguridad y, en ocasiones, rechazo a todo aquel que sea diferente 0 que pertenezca a aquellas culturas similares a la de los terroristas.

Figura 10. La llegada de refugiados puede fomentar el racismo y los movimientos xenófobos

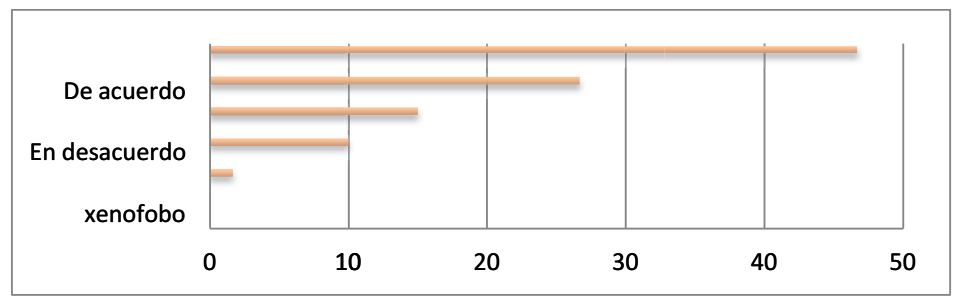


En otro orden de cosas, gran parte del conocimiento que tenemos acerca de la problemática proviene de los medios de comunicación, por ello, preguntamos si creen que las noticias que nos llegan a través de ellos son veraces. Un mayoritario $41,67 \%$ de los sujetos no sabe decirnos si, realmente, podemos considerar a los medios de comunicación como recursos totalmente veraces o no. Por el contrario, el $23,33 \%$ y el $26,67 \%$ opinan que son poco o nada veraces y un escaso $6,67 \%$ y 1,67\% están de acuerdo o totalmente de acuerdo, respectivamente, con la aseveración (ver Figura 11). En este aspecto, ni la edad ni el género nos muestran datos relevantes, ya que las diferencias son mínimas.

Figura 11. Las noticias que nos llegan al respecto y que nos transmiten los medios son veraces

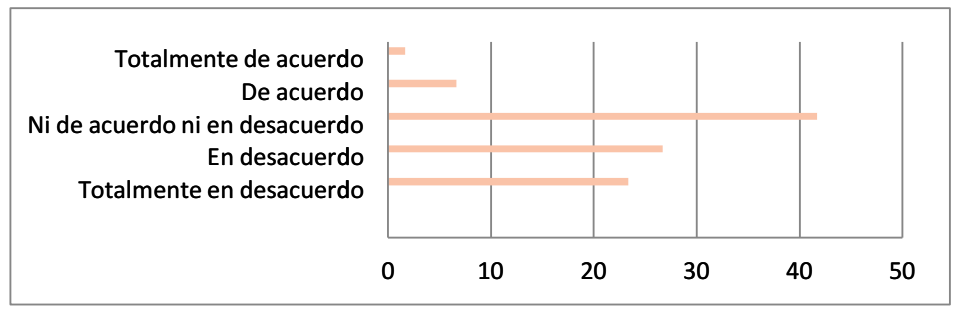

Por su parte, ¿estarán los integrantes de la muestra de acuerdo con la política del cierre de las fronteras para impedir la entrada de personas que buscan refugio? Al respecto, como se representa en la Figura 12, el 11,67 \% y el 36,67\% están en desacuerdo o muy en desacuerdo, respectivamente, con esta medida, mientras que el $31,67 \%$ afirman estar de acuerdo con ella. En el punto medio, un $20 \%$ no sabe posicionarse.

Figura 12. Han de cerrarse las fronteras para impedir la entrada de personas que buscan refugio

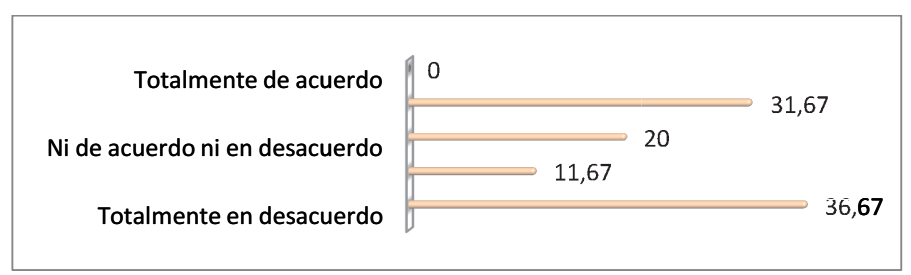

Si atendemos a la variable edad (ver Tabla 1), descubrimos que son los menores de 25 años los que piensan de manera mayoritaria que las fronteras no deben cerrarse. Sin embargo, son los más mayores (entre 51 y 60 años y mayores de 60 ) los que opinan que sí hay que cerrarlas. A este respecto, observamos una sustancial diferencia en la manera de pensar entre los más jóvenes y los mayores. 


\section{GRADO DE CONOCIMIENTO SOBRE EL PROBLEMA DE LOS REFUGIADOS Y ACTITUDES HACIA ELLOS}

Tabla 1. Cierre de fronteras, según la edad

\begin{tabular}{|c|c|c|c|c|c|}
\hline & Totalmente en desacuerdo & En desacuerdo & Nide acuerdo ni en desacuerdo & De acuerds & T. Deacuerdo \\
\hline Menores de 25 & 21,67 & 0 & 6,67 & 3,33 & \\
\hline Entte $25 y 35$ & 3,33 & 6,67 & 3,33 & 6,67 & \\
\hline Entre 36 y50 & 3,33 & 3,33 & 3,33 & 5 & 0 \\
\hline Entre $51 y 60$ & 5 & 0 & 6,67 & $8,3,3$ & \\
\hline Mayores de 60 & 3,33 & 1,67 & 0 & 833 & \\
\hline
\end{tabular}

Cabe señalar que algunos países, como es el caso de Hungría, ya han llevado a cabo medidas como ésta para impedir la entrada de refugiados a sus países, además de aumentar los controles y la seguridad en las zonas fronterizas e incluso ha llegado a barajarse la posibilidad de paralizar temporalmente el Tratado de Schengen.

Finalmente, indagamos sobre la atención que prestan a las noticias relacionadas con las personas que salen de sus países en busca de refugio. Como se representa en la Figura 13, el 51,67\% de la muestra refiere no prestarle ni más ni menos atención que al resto de noticias. Por el contrario, el $30 \%$ y el $15 \%$ están de acuerdo o totalmente de acuerdo, respectivamente en que sí le prestan atención y tan sólo un 3,33\% confiesa no prestarle atención a las noticias sobre refugiados.

Figura 13. Presto atención a las noticias sobre refugiados

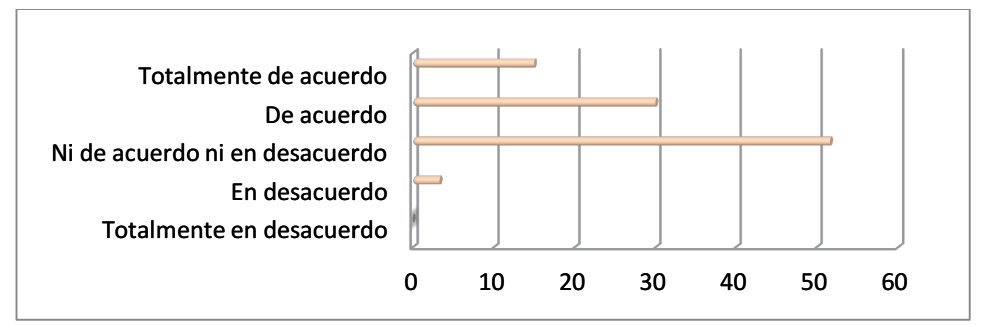

\section{CONCLUSIONES}

Los ciudadanos de la muestra analizada son capaces, en su mayoría, de distinguir a un refugiado y a un inmigrante. No obstante, pese a la actualidad y relevancia del tema, todavía un sustancial número de personas no tiene clara la diferencia entre estos términos.

Se reconoce que la causa del éxodo masivo es la guerra que sufren en sus países y que debido a ello su vida corre un grave peligro. Los solicitantes de asilo no llegan a nuestros países buscando unas condiciones de trabajo excepcionales 0 creyendo que tienen más derechos que los nativos, sólo buscan un lugar seguro donde puedan vivir y conseguir una manera de mantenerse dignamente sin necesidad de subsidios. Pero no todo el mundo parece tener esta visión ya que, como hemos comprobado, algunos creen que no deberíamos permitir su entrada en Europa ni darles "tantas" ayudas e, incluso, que puede llegar a constituir una amenaza.

Por este motivo, son necesarios profesionales cualificados para que muestren la verdadera realidad, qué derechos tenemos todos como ciudadanos y cuáles son los derechos de los refugiados $y$, de igual manera, para educar en valores como el respeto a las diferentes culturas y religiones, la tolerancia y la empatía. En este sentido, la educación es un derecho básico. Teniendo en cuenta que educación no es sólo el periodo que pasamos en la escuela y demás sistemas formales, sino que es 
un elemento fundamental para nuestro desarrollo personal y social y que, por tanto, es un proceso que se da durante toda la vida, los ciudadanos debemos involucrarnos para crear una sociedad justa.

Además, es necesario fomentar la sensibilización, la participación y el nivel de implicación de los ciudadanos, así como publicitar y visibilizar más a las entidades, organizaciones e instituciones que trabajan en este ámbito.

A lo largo de la investigación, hemos encontrado con algunas dificultades, especialmente para conseguir que las personas respondieran al cuestionario y obtener una muestra significativa, ya que ha habido muchas negativas a ello, generalmente muy rotundas.

La problemática que sufren los refugiados no es una novedad. Si echamos una mirada al pasado veremos que ya ha habido otras épocas en las que se han producido éxodos. Sin embargo, en la actualidad nos ha tocado vivir una grave crisis humanitaria, de la cual tenemos o podemos tener conocimiento y detalles casi a tiempo real y no por mirar hacia otra parte desaparece. Los seres humanos estamos destinados a sufrir cambios a lo largo de nuestras vidas, algunos serán positivos y otros nos afectarán de manera negativa, pero debemos aprender de ellos y seguir adelante, conviviendo 0 aprendiendo a convivir con los demás con respeto, armonía y paz. Sin embargo, los países europeos se han visto sobrepasados con la crisis de los refugiados y, en muchos casos, no saben qué medidas tomar de manera efectiva para solventarla.

Los refugiados salen de sus países en busca de vida, lo abandonan todo para poder vivir con seguridad. Desgraciadamente muchos de ellos perecen en el camino y otros muchos no encuentran la vida que esperaban conseguir en los países receptores, encontrando desinterés, prejuicios 0 manifiesta incomprensión.

\section{REFERENCIAS BIBLIOGRÁFICAS}

ACNUR. (s.f.). Solicitantes de Asilo. Recuperado de http://www.acnur.org/a-quien-ayuda/solicitantes-de-asilo/

ACNUR (2005) ¿Quién es un refugiado? Recuperado de http://www.acnur.org/a-quien-ayuda/refugiados/quien-es-un-refugiado/

ACNUR (2008). La protección de los refugiados y el papel de ACNUR. Recuperado de http://acnur.es/PDF/7029_20120511114659.pdf

Comité Español ACNUR (s. f.). ¿Cuáles son los derechos de los refugiados en el mundo? Recuperado de http://recursos.eacnur.org/gracias-dere-educacion-nic3b1os-refugiados? submissionGuid=297276e6-dde7-47c0-bd0d-9f0fce62c3e6

Naciones Unidas (1951, 28 julio). Convención sobre los Refugiados. Ginebra 
